\title{
HEARTRATE CALCULATOR
}

\author{
Raymond J. TRUdnowski, M.D. *
}

THE EKG oscilloscope has become a standard fixture in the operating room. It is most useful in detecting potentially dangerous arrhythmias during anaesthesia. ${ }^{1-3}$

Another function of this apparatus which is frequently overlooked, is the determining of heart rate. This can be done by counting QRS complexes for a definite time interval and extrapolating the result to one minute. Another way makes use of a tachometer triggered by $R$ waves.

We have devised a third method which is simple and inexpensive. It uses the following equation for determining heart rate:

$$
\begin{aligned}
& \mathrm{R}=\mathrm{YZ} \\
& \mathrm{R}-\text { heart rate per } 60 \text { seconds } \\
& \mathrm{Y} \text { - number of sweeps of the oscilloscope in } 60 \text { seconds } \\
& \mathrm{Z} \text { - number of cardiac cycles in one sweep of the oscilloscope }
\end{aligned}
$$

Solution of this equation involves two measurements and the use of the nomogram described below. The diameter of the oscilloscope is measured with a centimeter ruler at the beginning of the operation. The number of R-R intervals per sweep of the oscilloscope is counted for each determination to provide a value for factor $\mathrm{Z}$. Factor $\mathrm{Y}$, called the multiplier is obtained from the nomogram we have constructed as follows:

When the scanning speed is $25 \mathrm{~mm}$ or $2.5 \mathrm{~cm} / \mathrm{sec} \mathrm{Y}$ can be determined from the equation

$$
\begin{aligned}
& \mathrm{Y}=60 /(\mathrm{X} / 2.5) \\
& \mathrm{XY}=150
\end{aligned}
$$

where $\mathrm{X}$ is the diameter of the oscilloscope in centimeters.

This is the equation of an equilateral hyperbola. The function is discontinuous at 0 . We used the positive portion of the hyperbola in designing the nomogram. This gives $\mathrm{Y}$ by a simple graph plot. This value is used for all the rate calculations.

In practice, we estimate the cycles in one sweep to the nearest half cycle. If the scanning speed is $12.5 \mathrm{~mm} / \mathrm{sec}$, the multiplier obtained is halved. If the speed is $50 \mathrm{~mm} / \mathrm{sec}$, it is doubled.

This method of determining heart rate allows the observer to monitor changes in heart rate more frequently, several times a minute if necessary. It also avoids

"Department of Anesthesiology, Roswell Park Memorial Institute, New York State Department of Health, 666 Elm Street, Buffalo, New York 14203. 
PULSE RATE CALCULATOR

(SCAN SPEED $25 \mathrm{~mm} / \mathrm{sec)}$

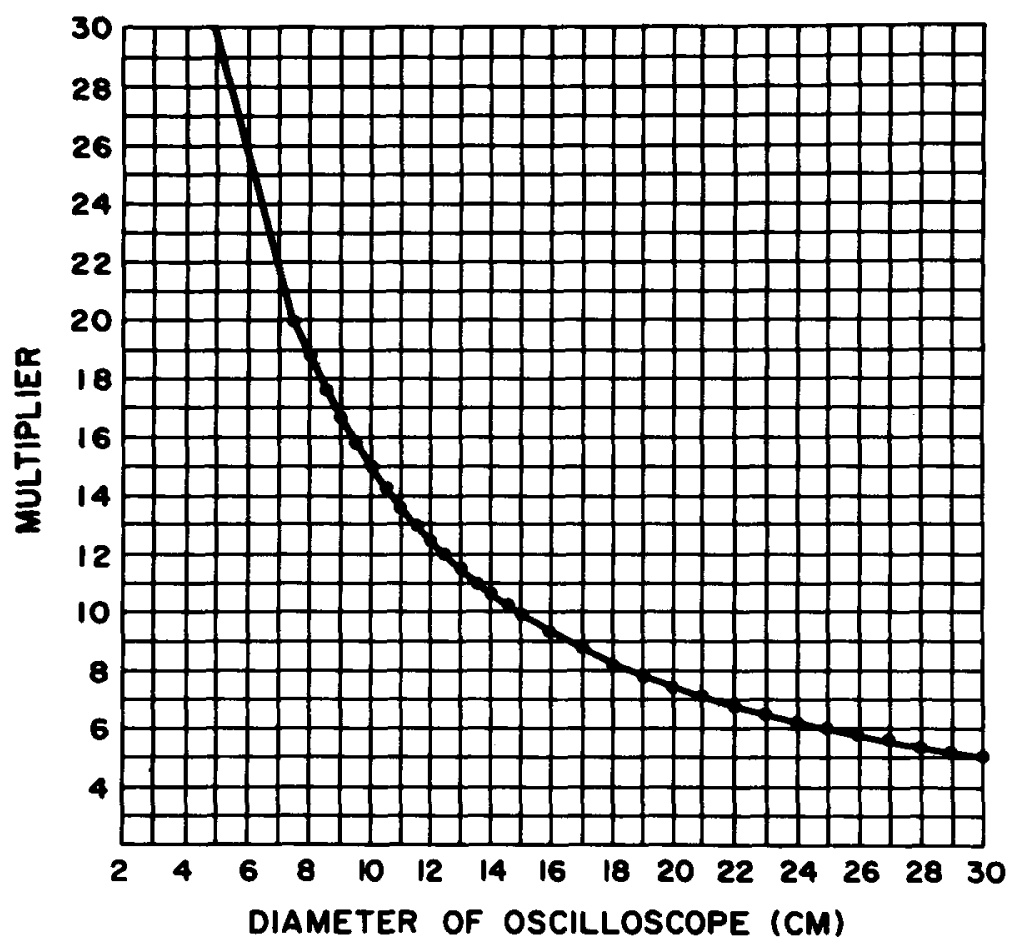

the problem of trying to coordinate the second hand on the clock with a count of QRS complexes on the tube.

Of course, any heart rate obtained from the electrical activity of the heart should be correlated with periodic blood pressure measurements and checks on the quality of the pulse to make certain the cardiac output is adequate. ${ }^{1.4}$

\section{SUMMary}

A nomogram is described which allows the rapid calculation of heart rate from oscilloscopes of various sizes. Only two measurements are necessary: the diameter of the oscilloscope in centimeters, and the number of R-R intervals in one sweep of the oscilloscope. Closer monitoring of the heart rate is possible without the use of expensive attachments.

\section{RÉSUMÉ}

Nous présentons un nomogramme qui permet une calculation rapide du vitesse des battements cardiaque à l'aide d'oscilloscopes de différentes dimensions. Seulement deux données sont requises : le diamètre de l'oscilloscope mesuré en centi- 
mètres et le nombre d'intervalles R-R contenue dans un seul balayage de l'oscilloscope. Il est ainsi possible de surveiller plus attentivement le vitesse des battements cardiaque sans nécessité d'équipement additionel dispendieux.

\section{REFERENCES}

1. Cannard, R.H., Dripps, R.D., Helwig, J., Zinsser, H.F. Electrocardiogram during anesthesia and surgery. Anesthesiology 21: 194-202 (1960).

2. RusselL, P.H. \& CoAKLEY, C.S. Electrocardiographic observation in the operating room. Anesthesia and Analgesia 48: 784-788 (1969).

3. HaldemanN, G. \& Schaer, H. Haemodynamic effects of transient atrioventricular dissociation in general anaesthesia. Brit. J. Anaesth. 44: 159-162 (1972).

4. Rusmmer, R.F. Cardiovascular Dynamics, 2nd ed. Philadelphia: Saunders (1961).

Canadian Anaesthetists' Society Prize - 1972

\section{ERRATUM}

The Canadian Anaesthetists' Society Prize for 1972 was awarded to Dr. Douglas B. Craig, Dr. W.M. Wahba, and Dr. Hillary Don for their paper entitled "Airway Closure and Lung Volume in Surgical Positions" in Canadian Anaesthetists' Society Journal 18: 92-99, January 1971, and not as announced in the Journal in Volume 19: 676 (November 1972). We apologize to the Authors and to the Adjudication Committee for this error. 